\title{
Glycotoxines, Carbonyl Stress and Relevance to Diabetes and Its Complications
}

\author{
Z. TURK ${ }^{1}$ \\ ${ }^{1}$ Vuk Vrhovac University Clinic for Diabetes, Zagreb, Croatia
}

Received April 23, 2008

Accepted March 10, 2009

On-line June 19, 2009

\begin{abstract}
Summary
A large body of evidence has implicated reactive carbonyl compounds as glycotoxic mediators of carbonyl stress. This review is focused on the pathophysiological effects of $\alpha$-oxoaldehydes in diabetes and related complications, summarizing the state-of-the-art on the endogenously produced carbonyls methylglyoxal, glyoxal and 3-deoxyglucosone, formed as glycolytic intermediates during metabolic conversion of glucose, via Maillard reaction by degradation of glycated proteins, and during lipid peroxidation process. Their role in the advanced glycation process and detrimental effects on vascular tissue are discussed.
\end{abstract}

\section{Key words}

Diabetes - Carbonyl stress - Methylglyoxal - Glyoxal • 3-deoxyglucosone • Advanced glycation end-product

\section{Corresponding author}

Z. Turk, Vuk Vrhovac University Clinic for Diabetes, Dugi dol 4A, HR-10000 Zagreb, Croatia. Fax: +385(1) 23315 15. E-mail: zturk@idb.hr

\section{Introduction}

Glycation process leading to advanced glycation end-product (AGE) formation has been identified as a biologic phenomenon in the pathogenesis of diabetes and its complications (Brownlee 2005, Huebschmann et al. 2006, Ahmed and Thornalley 2007). AGE-proteins are formed by post-translational modification when blood glucose reacts with free amino groups of amino acids, peptides, phospholipids and nucleic acids. This chemical reaction between an amino group and carbonyl group of reducing sugar is not enzymatically catalyzed. It is a covalent interaction, generally termed nonenzymatic glycosylation. The term glycation is arbitrary adopted to distinguish this type of chemical reactions from many other N- or O-glycosylations.

French chemist L.C. Maillard conducted pioneer work on sugar-amino acid condensation (Maillard 1912) and this type of reaction has been termed after him in chemical nomenclature. In the course of Maillard reaction, the first formed Schiff base adduct is converted to a more stable Amadori rearrangement product. These Amadori products then undergo further rearrangement to form irreversibly bound AGEs, in a cascade of chemical reactions. The intermediate stage of Maillard reaction is characterized by the formation of numerous secondary products. The sugar moiety of an early glycation product can undergo chemical reactions, consequently producing low molecular weight carbonyls such as methylglyoxal, glyoxal and 3-deoxyglucosone. These reactive carbonyls again react with free amino groups, leading to crosslinking and formation of AGEs in the late stage of Maillard reaction (Finot 1982). AGEs represent a potpourri of very heterogeneous chemical structures, and a number of them have been detected in body proteins (Thorpe and Baynes 2003).

In vivo, AGE-modified proteins have been found to be involved in the development of vascular lesions, thus potentially contributing to micro- and macrovascular pathology. Glycated hemoglobin (HbA1c) determination has been accepted as a standard measure of glycemia 
control and risk marker of long-term complications in diabetes (DCCT 1993, Genuth et al. 2002). A significant increase in HbAlc level is a consequence of hyperglycemia. However, glucose per se appears to be by far less potent in the formation of AGE-proteins than glycotoxins, the intermediary metabolites of $\alpha, \beta$-dicarbonyl structure. This review summarizes current evidence on the physiologically produced carbonyl compounds methylglyoxal, 3-deoxyglucosone and glyoxal, their role in the advanced glycation process, and detrimental effects on vascular tissue.

\section{$\alpha$-Oxoaldehydes as AGE precursors}

Endogenously formed $\alpha$-oxoaldehydes are potent glycating agents acting as key factors in the phenomenon called carbonyl stress (Thorpe et al. 2000). In fact, carbonyl stress results from impaired balance between the generation of carbonyl intermediates and efficiency of scavenger pathway. Dicarbonyls, in general, are formed as i) glycolytic intermediates in metabolic conversion of glucose, ii) via Maillard reaction by degradation of glycated proteins, and iii) during lipid peroxidation (Fig. 1). Whereas glucose is involved in glycation reactions exclusively in its aliphatic form, accounting for only $0.001 \%$ of total glucose concentration, $\alpha$-oxoaldehydes are characterized by extremely high chemical activity. They are up to 20,000-fold as reactive as glucose, thus being able to form AGE-structures even at very low concentrations. Physiologically, $\alpha$-oxoaldehydes react directly with protein terminal amino acid residues. The potency of $\alpha$-oxoaldehydes in glycation under physiologic conditions was demonstrated by in vitro incubation of $1 \mu \mathrm{mol} / 1\left({ }^{14} \mathrm{C}\right)$ methylglyoxal in human plasma (Thornalley 2005). All the methylglyoxal was irreversibly bound to plasma proteins after $24 \mathrm{~h}$. It has been postulated that the biogenesis of these intermediary metabolites is not exclusively dependent on persistent hyperglycemia but may also be influenced by glycemia fluctuation. It appears that reactive $\alpha$-oxoaldehydes can discretely promote the pathology of diabetic complications, even in the presence of good glycemia control, as indicated by HbA1c ( $\leq 8 \%)$. Evaluation of physiologic $\alpha$-oxoaldehydes has not yet been fully investigated, mostly due to the complex methods of detection. However, their role has been postulated in the carbonyl stress reactions, which activate a series of inflammatory responses leading to accelerated vascular damage in diabetes and end-stage renal disease.

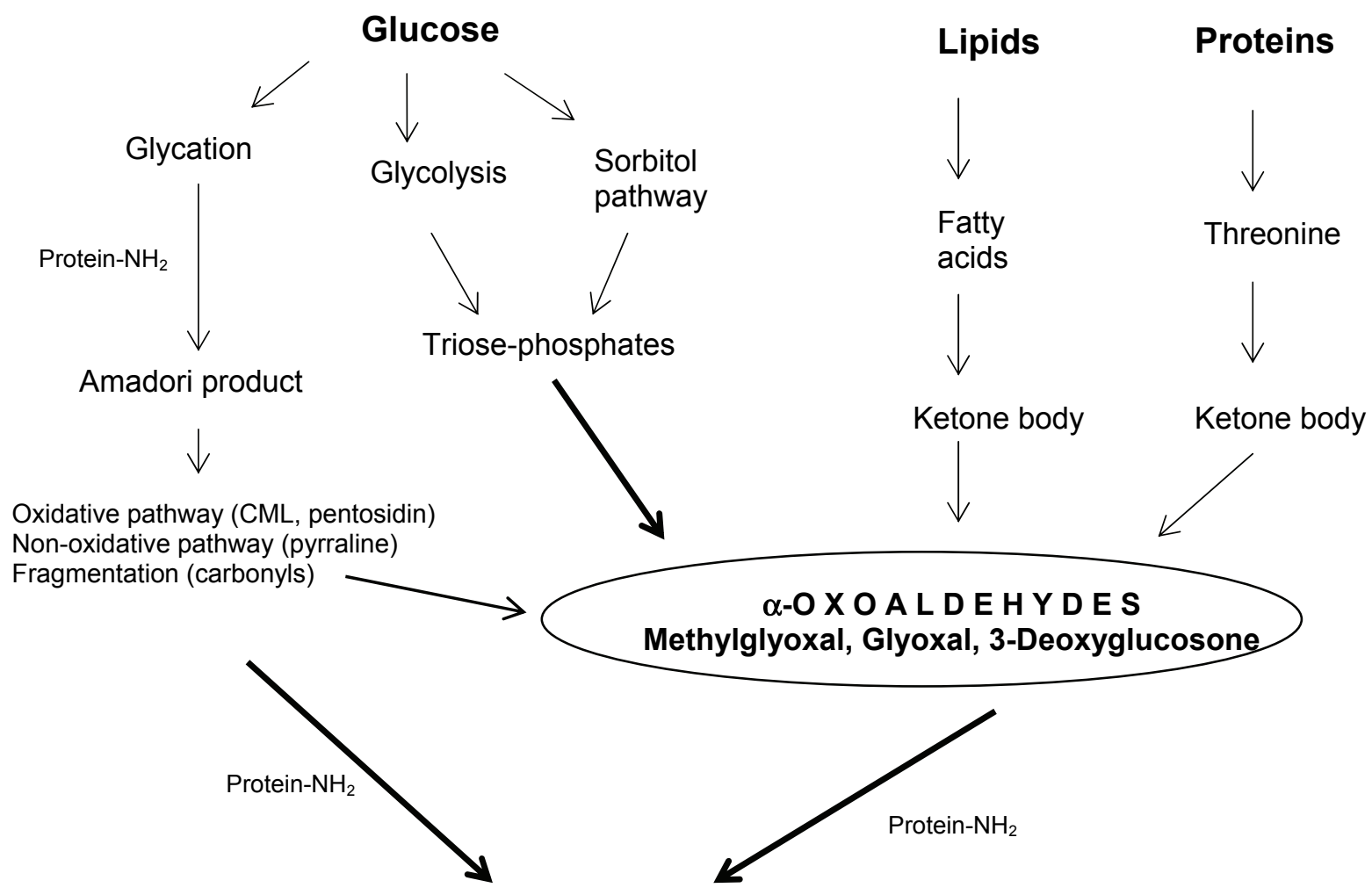

ADVANCED GLYCATION END-PRODUCTS

Fig. 1. Reaction scheme for reactive carbonyl compounds biogenesis. 


\section{Methylglyoxal}

\section{Biogenesis}

Methylglyoxal (MG) is a distinctive representative of $\alpha$-oxoaldehyde compounds, generated intracellularly in all mammalian cells, through both enzymatic and non-enzymatic pathways. The majority of MG production occurs from the triose phosphate intermediates in the glycolytic pathway, which includes fragmentation and elimination of phosphate from glyceraldehyde-3-phosphate and dihydroxyacetone phosphate (Richard 1993). It is also formed in the ketone body metabolism and in the catabolism of threonine. MG is very reactive, but its interactions with body proteins and nucleic acids are controlled by glyoxalase (Thornalley 1998). The glyoxalase system is present in the cytosol of all mammalian cells. It consists of two enzymes, glyoxalase I and glyoxalase II, and a catalytic amount of reduced glutathione (GSH). Physiologic $\alpha$-oxoaldehydes, $\mathrm{MG}$ and glyoxal are metabolized by glyoxalase pathway. The metabolism of MG leads to the production of the inert end-product D-lactate (Thornalley 2003). The concentrations of $\alpha$-oxoaldehydes in human tissues and body fluids are usually low. For example, the concentrations of glyoxal and $\mathrm{MG}$ in human blood samples were 211 and $80 \mathrm{pmol} / \mathrm{g}$, respectively (Thornalley 1998). In terms of pathophysiology, such low concentrations of $\alpha$-oxoaldehydes are protective because of the carbonyl high reactivity with nucleic acids and body proteins. The glyoxalase system in situ suppresses irreversible modifications of DNA, RNA and amino acid residues by the action of $\alpha$-oxoaldehydes. The accumulation of $\alpha$-oxoaldehyde-derivative nucleic acids is associated with mutagenesis and may promote cell apoptosis. Under physiological conditions, MG can form MG-derivative AGE structures accumulated on humoral and tissue proteins. For example, $\mathrm{MG}$ readily binds and modifies arginine, lysine and cysteine residues in protein, and intracellularly reacts with nucleic acids, participating in the formation of a variety of AGEs (Lo et al. 1994). MG-induced AGEs on mitochondrial proteins lead to a decline of mitochondrial function and have been hypothesized to act as a contributing factor in the phenomenon of so-called "metabolic memory" (Ihnat et al. 2007).

Metabolic disorders such as diabetes can induce an increase in the $\mathrm{MG}$ formation. Increased $\mathrm{MG}$ production arises mainly from hyperglycemia (Brownlee 2001) in cells accumulating high level of glucose. This might be additionally exacerbated by low glyceraldehyde-3-phosphate dehydrogenase activity (Beisswenger et al. 2003 a,b). In fact, the rate-controlling enzymes of the glycolytic pathway modulate up and downstream of MG. Intracellularly produced MG crosses cell membranes, probably by passive diffusion, and humoral MG is mainly cell-derived. Additionally, minor amounts of MG might arise from ketone body metabolism, degradation of threonine, and lipid peroxidation. The sustained increase in the MG level may also be the consequence of decreased clearance by the glyoxalase system. Optimal activity of the glyoxalase system is dependent on the adequate level of reduced glutathione (GSH). In diabetes, both hyperglycemia and oxidative stress are associated with GSH depletion. This may entail impaired detoxification of $\mathrm{MG}$ and consequently its increased production in diabetic state.

The possible sources of MG include the catabolism of threonine via aminoacetone (Lyles and Chalmers 1992). The catabolism of threonine normally produces glycine and acetyl-CoA, but in a low CoA state such as diabetic metabolic crisis, where much of the CoA is in the form of acetyl-CoA, threonine is catabolized to aminoacetone (Tressel et al. 1986). Enzymatic oxidation of ketone bodies (acetoacetate and acetone) can also generate $\mathrm{MG}$. Its production from acetoacetate is mediated by myeloperoxidase, whereas P450 2E1 cytochrome catalyzes acetone conversion into $\mathrm{MG}$ (Kalapos 2003). In healthy people, it has been shown that the popular and widely used Atkins diet, characterized by low carbohydrate intake, leads to a significant increase in MG level (Beisswenger et al. 2005a,b). The highly significant relationship between $\mathrm{MG}$ and acetol levels, demonstrated by the same authors, suggests that $\mathrm{MG}$ is produced directly from acetol by oxidative mechanisms. Although ketone bodies are likely to be an important source of $\mathrm{MG}$, it is also possible that some MG is derived from increased triose phosphate resulting from the increased production of glycerol caused by accelerated triglyceride breakdown, or from lipoxidation products (Baynes and Thorpe 2000).

The sustained increase in the MG level may also be the consequence of decreased clearance by detoxification pathways. Several enzymes are involved in detoxification of $\mathrm{MG}$ and make a network of four recognized catabolism pathways, as follows: the glyoxalase system, aldose reductase, betaine aldehyde dehydrogenase, and 2-oxoaldehyde dehydrogenase (Nemet et al. 2006). 
Importantly, diet is an underestimated source of distinct AGE derivatives (Huebschmann et al. 2006). In humans with or without diabetes, a meal with high AGE content was shown to lead to its elevation in plasma. Some $10 \%$ of AGEs ingested are absorbed into the body's circulation, and over $65 \%$ of those absorbed are retained (Koschinsky et al. 1997). The influence of diet on serum MG level was also demonstrated in renal failure patients (patients with diabetes were excluded). It was shown that a high dietary AGE intake increased serum MG (26\%) in contrast to a diet with low AGE intake, which caused a decrease in serum MG (35\%) (Uribarri et al. 2003).

MG has been postulated to play a role in the development of hypertension (Chang and $\mathrm{Wu}$ 2006). Studies using animal model and cell cultures showed a significant increase in blood pressure to coincide with elevated MG level in plasma and aortic tissues (Wang et al. 2004, 2005). However, functional links between MG biogenesis and hypertension, in part mediated by ROS and AGEs, have only been documented in rat model but not yet in humans under these conditions.

\section{Significance in diabetes}

It is considered that monitoring of $\mathrm{MG}$ biogenesis in diabetic patients might help to assess the risk of progression of diabetic complications. Under physiological conditions, MG exists in two forms, i.e. as a free dicarbonyl compound (unbound form) and bound to protein residues, known as MG-derivative AGEs. MG in the free form is very unstable, has short biological survival, and sophisticated techniques are required for its quantitative evaluation. Our results of free MG measurement have shown excessive production in diabetic state, detected in both plasma and whole blood samples (Nemet et al. 2005). We found MG overproduction to correlate tightly with glycemia fluctuation. Glycemic lability is one of the known risk factors in the progression of diabetic complications (Beisswenger et al. 2001). In another recent study, we observed MG biogenesis in the course of diabetic ketoacidosis and recorded an extremely high MG production during the first $24 \mathrm{~h}$ of metabolic crisis (Turk et al. 2006). $\mathrm{MG}$ as a side-product of glycolysis consequently arises from an increased flux during hyperglycemia. However, the treatment for ketoacidosis and glycemia control failed to produce significant $\mathrm{MG}$ reduction toward control values of diabetic population in general. This observation suggests involvement of other
MG sources, probably ketone body metabolism. It is postulated that ketone bodies might be alternative $\mathrm{MG}$ precursors not only in ketoacidosis but also in poor diabetes control. The involvement of ketone body metabolism may explain why type 1 diabetic patients suffer the highest level of MG (McLellan et al. 1994). In addition, the above study of MG production during ketoacidosis supports the hypothesis that other toxic metabolites that are actively involved in post-translational protein modifications are probably generated in acute metabolic crisis. Therefore, excessive production of glycotoxic intermediates such as $\alpha$-oxoaldehydes or other $\alpha, \beta$-dicarbonyls may be a link connecting an acute metabolic event with accelerated tissue damage, a feature characteristic of long-term complications of diabetes.

As emphasized above, due to the extremely high chemical reactivity, the physiologically produced $\mathrm{MG}$ participates in the formation of MG-derivative AGE structures. Imidazolone adducts are formed in reaction with arginine residues, whereas carboxyethyllysine (CEL) and MG-lysine dimer (MOLD) are formed in reaction with lysine residues. A recent study by Ahmed et al. (2005) has demonstrated that hydroimidazolones are the most important biomarkers of advanced glycation process. This study has offered evidence that the majority of AGE in plasma proteins of diabetic and non-diabetic subjects are hydroimidazolones. In diabetic patients, the level is significantly higher, and the largest quantitative increase in protein glycation adducts of plasma protein occurs as structural isomers of $\mathrm{MG}$ and 3-DG derivative hydroimidazolones. In hemoglobin, $\mathrm{MG}$ and 3-DG derivative hydroimidazolones are, again, the major glycation adducts in quantitative sense. The authors reported that diabetes type 1 under moderate metabolic control is associated with a profound increase of plasma level and urinary excretion of protein glycation and oxidation free adducts, particularly MG-derivative hydroimidazolone. MG-derivative adducts are excreted in the urine. As reported by Ahmed et al. (2005), urinary excretion of a variety of AGE-compounds increased up to 15-fold in diabetic patients. Considering renal function and MG-adduct level, we found a significant inverse correlation between plasma MG-derivative AGEs and creatinine clearance (Nemet et al. 2005). Elevation of plasma MG was also observed in non-diabetic patients with mild to moderate renal failure and in patients on hemodialysis (Beisswenger et al. 2005a,b). These results suggest that renal function might affect the clearance of plasma MG-derivative AGE and consequently influence 
its concentration in the blood stream.

\section{Relevance to diabetic complications}

The knowledge of advanced glycation endproducts has considerably expanded over years, and a large body of evidence has documented their implication in diabetes-related complications (Singh et al. 2001, Turk et al. 2001, Brownlee 2005, Monnier et al. 2005, Huebschmann et al. 2006). The recently recognized relationship between $\alpha$-oxoaldehydes and biologically important macromolecules highlights the intermediate step of advanced glycation cascade (Beisswenger et al. 2003a,b, Thornalley 2005). The involvement of MG in modification of tissue proteins has been demonstrated in diabetes and uremic patients by means of immunohistochemistry and immunochemistry (Bourajjaj et al. 2003). However, structural and functional modification of host-protein is a common feature of all AGEs irrespective of their generating precursors. Through their effects on the functional properties of extracellular matrix, intracellular signal transduction and protein function, AGEs may contribute to the pathogenesis of diabetic retinopathy (Pokupec et al. 2003), neuropathy (Misur et al. 2004), renal failure (Makita et al. 1994, Turk et al. 2004, Rabbani et al. 2007) and macrovascular disease (Turk et al. 2003) (for detailed reviews on glycation and complications of diabetes see Turk 1997 and Turk 2001).

A mechanism by which AGE-modified proteins may exert their effect is binding to AGE-specific cellsurface receptors (RAGE) identified on a variety of cells including endothelial and smooth muscle cells, and by internalization and degradation via monocyte/ macrophage AGE-receptors. Increased RAGE expression has been found on endothelial cells, vascular smooth muscle cells and cardiac myocytes of diabetic patients (Schmidt et al. 1999). It has been reported that ligation of AGE with RAGE causes activation of intracellular signaling, gene expression, and production of proinflammatory cytokines and free radicals, thus playing an important role in the development and progression of diabetic micro- and macroangiopathy (Kim et al. 2005). A fundamental observation in human diabetes was reported by Cipollone et al. (2003). These authors found that up-regulated RAGE expression in diabetic atherosclerotic plaques retrieved from human subjects co-localized with a range of pro-oxidant and inflammatory markers. They also showed that the increased expression of RAGE in the plaques correlated linearly with the glycated hemoglobin level, suggesting that RAGE expression is correlated with the degree of ligand accumulation.

Considerable progress has been made in the understanding the AGEs/RAGE action in the past few years. Unifying outcomes of RAGE engaged with its ligand family in inflammatory and vascular cells is up-regulation of cascade of proinflammatory cytokines, growth factors, adhesion molecules and matrix metalloproteinases, with multiple consequences in the tissues and organs (Ramasamy et al. 2008). Recent studies have revealed the role of AGEs and their receptors, in the pathogenesis of diabetic nervous system complications (Lukic et al. 2008). Increasing evidence indicates that RAGE with its ligands can initiate and sustain significant cellular perturbations in the inner and outer retina, as a relevant pathway leading to the pathogenesis of diabetic retinopathy (Wang et al. 2008). When made diabetic, RAGE-overexpressing transgenic mice exhibited exacerbation of the indices of nephropathy, while RAGE-deficient animals showed amelioration of diabetic nephropathy (Yamamoto et al. 2007). Genetic variation in the gene coding for RAGE may alter gene expression and function of the receptor and affect diabetic vascular disease development and outcome. Investigation of the association between RAGE polymorphisms and parameters of glucose homeostasis indicated that gene polymorphisms might contribute to the development of insulin resistance and diabetes (Gaens et al. 2008). Therefore, a therapeutic interruption of AGEs and/or AGE-RAGE interactions seems to be a logical approach for reducing diabetic complications sequelae.

\section{3-Deoxyglucosone}

\section{Biogenesis}

3-Deoxyglucosone (3-DG) is a small molecular weight aliphatic aldehyde of potential physiological significance, which has been demonstrated to participate in adduct formation with proteins. The biogenesis of 3-DG in humans occurs via Maillard reaction in its intermediate stage, and also from fructose-3-phosphate through the polyol pathway. Physiologically produced 3-DG was detected in the lens and hearts of diabetic rats and in an increased level in erythrocytes of diabetic hemodialysis patients (Lal et al. 1995, 1997, Tsukushi et al. 1999). 3-DG reacts rapidly with protein amino residues forming 3-DG-related AGEs such as 
carboxymethyllysine (CML), 3-DG-imidazolone, pyrraline, and pentosidine as a minor product (Niwa et al. 1999). 3-DG-imidazolone and pyrraline are considered to be markers of the presence of 3-DG derivative AGEs in vivo. There is evidence that $3-\mathrm{DG}$-imidazolone is the major product in 3-DG derivative AGEs (Ahmed et al. 2005, Jono et al. 2004). 3-DG itself shows certain biological activities such as the induction of apoptosis, suppression of cell proliferation and induction of heparinbinding of epidermal growth factor-like growth factor, which acts as a potent mitogen in aortic smooth muscle cells (Niwa et al. 1999). Moreover, 3-DG, likewise MG, inactivates glutathione reductase that enhances the potential for oxidative damage, and also inhibits the activities of hepatic enzymes responsible for glucose metabolism.

\section{Clinical relevance}

In humans, 3-DG is involved in aging and plays an important role in the end-stage renal disease and pathogenesis of diabetic complications. Its plasma level was found to be increased in uremic patients as well as in diabetic patients (Niwa et al. 1995, Hamada et al. 1997). Investigations based on plasma measurement of 3-DG and its urinary metabolite 3-deoxyfructose have suggested a relationship between impaired detoxification of this carbonyl compound and early nephropathy development (Wells-Knecht et al. 1994). 3-DG involvement in modification of tissue proteins has been demonstrated by immunohistochemistry and immunochemistry in diabetic and uremic patients. Niwa et al. (1997) demonstrated 3-DG-imidazolone to accumulate in nodular lesions and to expand mesangial matrix of the glomeruli and renal arteries in advanced stages of diabetic nephropathy as well as in atherosclerotic lesions of the aorta. Pyrraline has been detected in sclerosed glomeruli, arteries affected with arteriosclerosis and senile plaques of patients with Alzheimer's disease. Higher pyrraline content was demonstrated in cataractous lenses as compared with agematched controls (Nagaraj and Sady 1996). 3-DG derivative AGE structures were localized not only in the extracellular matrix but also in intracellular lesions. 3-DG-imidazolone and carboxymethyllysine might be recognized by AGE receptor expressed on macrophages and smooth muscle cells, and taken up into intracellular lesions, inducing expression of cytokines and growth factors that contribute to the pathology of diabetic vascular disease.

\section{Other dicarbonyls}

The second step of Maillard reaction is characterized by the formation of numerous secondary products. The sugar moiety of an early glycation product can undergo enolization, followed by dehydration, oxidation and/or fragmentation reactions, consequently producing dicarbonyls and other low molecular weight compounds (Finot 1982). Most of the products formed are by far more reactive than the precursor molecules. As reported by Thornalley (2005), from this cascade of reactive intermediates, eleven dicarbonyl compounds are currently being investigated for their role in glycation in food chemistry or for their physiological relevance.

Glyoxal is definitely an interesting issue in the context of carbonyl stress and its physiological significance in diabetes. In addition to Maillard reaction, glyoxal is a side product of lipid peroxidation. It is important as a glycation agent in physiological systems and a precursor of AGEs. A specific glyoxal-derived AGE is a lysine-lysine crosslinking structure named glyoxal-lysine dimer or GOLD. Investigators have reported an age-related increase of GOLD in human lens proteins as well as in diabetic state (Frye et al. 1998, Chellan and Nagaraj 1999, Shamsi and Nagaraj 1999, Sady et al. 2000). The rapid reaction of glyoxal with proteins may account for the difficulty in its measurement in biological samples (Nakajima et al. 2007). However, there are reports on significant increases of plasma glyoxal concentrations in uremic (Niwa et al. 1999) and diabetic patients (Lapolla et al. 2003, Han et al. 2007).

\section{Conclusion}

Protein glycation leading to AGE formation is enhanced in diabetes by increases in blood glucose perse, and collaterally, by the production of small molecular weight carbonyl compounds. The increased generation of glycotoxins occurs due to both alterations in cellular metabolism and inefficiency of the related scavenger mechanisms. From numerous reports presented, it is evident that physiologically $\alpha$-dicarbonyl compounds accelerate the kinetics of AGE formation, thus potentiating their detrimental effects in vascular pathophysiology.

\section{Conflict of Interest}

There is no conflict of interest. 


\section{References}

AHMED N, THORNALLEY J: Advanced glycation endproducts: what is their relevance to diabetic complications? Diabetes Obes Metab 9: 233-245, 2007.

AHMED N, BABAEI-JADIDI R, HOWELL SK, BEISSWENGER PJ, THORNALLEY PJ: Degradation products of proteins damaged by glycation, oxidation and nitration in clinical type 1 diabetes. Diabetologia 48: 1590-1603, 2005.

BAYNES JW, THORPE SR: Glycoxidation and lipoxidation in atherogenesis. Free Radic Biol Med 28: 1708-1716, 2000.

BEISSWENGER PJ, HOWELL SK, O'DELL RM, WOOD ME, TOUCHETTE AD, SZWERGOLD BS: $\alpha$-Dicarbonyls increase in the postprandial period and reflect the degree of hyperglycemia. Diabetes Care $\mathbf{2 4}$ : 726-732, 2001

BEISSWENGER PJ, HOWELL SK, NELSON RG, MAUER M, SZWERGOLD BS: alpha-Oxoaldehyde metabolism and diabetic complications. Biochem Soc Trans 31: 1358-1363, 2003a.

BEISSWENGER PJ, HOWELL SK, SMITH K, SZWERGOLD BS: Glyceraldehyde-3-phosphate dehydrogenase activity as an independent modifier of methylglyoxal levels in diabetes. Biochim Biophys Acta 1637: 98-106, $2003 \mathrm{~b}$

BEISSWENGER BG, DELUCIA EM, LAPOINT N, SANFORD, RJ, BEISSWENGER PJ: Ketosis leads to increased methylglyoxal production on the Atkins diet. Ann NY Acad Sci 1043: 201-210, 2005a.

BEISSWENGER PJ, DRUMMOND KS, NELSON RG, HOWELL SK, SZWERGOLD BS, MAUER M: Susceptibility to diabetic nephropathy is related to dicarbonyl and oxidative stress. Diabetes 54: 3274-3281, 2005 b.

BOURRAJJAJ M, STEHOUWER CDA, VAN HINSBERGH VWM, SCHALKWIJK CG: Role of methylglyoxal adducts in the development of vascular complications in diabetes mellitus. Biochem Soc Trans 31: 1400-1402, 2003.

BROWNLEE M: Biochemistry and molecular cell biology of diabetic complications. Nature 414: 813-820, 2001.

BROWNLEE M: The pathobiology of diabetic complications - a unifying mechanism. Diabetes 54: 1615-1625, 2005.

CHANG T, WU L: Methylglyoxal, oxidative stress, and hypertension. Can J Physiol Pharmacol 84: 1229-1238, 2006.

CHELLAN P, NAGARAJ RH: Protein crosslinking by the Maillard reaction: dicarbonyl-derived imidazolium crosslinks in aging and diabetes. Arch Biochem Biophys 368: 98-104, 1999.

CIPOLLONE F, IEZZI A, FAZIA M, ZUCCHELli M, PINI B, CUCCURULlO C, DE CESARE D, DE BLASIS G, MURARO R, BEI R, CHIARELLI F, SCHMIDT AM, CUCCURULLO F, MEZZETTI A: The receptor RAGE as a progression factor amplifying arachidonate-dependent inflammatory and proteolytic response in human atherosclerotic plaques: role of glycemic control. Circulation 108: 1070-1077, 2003.

DCCT (Diabetes Control and Complications Trial Research Group): Effect of intensive treatment of diabetes on the development and progression of long term complications in insulin dependent diabetes mellitus. $N$ Engl J Med 329: 977-986, 1993.

FINOT PA: Nonenzymatic browning products: physiologic effects and metabolic transit in relation to chemical structure. Diabetes 31 (Suppl 3): 22-28, 1982.

FRYE EB, DEGENHARDT TP, THORPE SR, BAYNES JW: Role of the Maillard reaction in aging of tissue proteins. Advanced glycation end product-dependent increase in imidazolium cross-links in human lens proteins. $J$ Biol Chem 273: 18714-18719, 1998.

GAENS KH, VAN DER KALLEN CJ, VAN GREEVENBROEK MM, FESKENS EJ, STEHOUWER CD, SCHALKWIJK CG: Receptor for advanced glycation end product polymorphisms and type 2 diabetes: the CODAM study. Ann NY Acad Sci 1126: 162-165, 2008.

GENUTH S, LIPPS J, LORENZI G, NATHAN DM, DAVIS MD, LACHIN JM, CLEARY PA: Effect of intensive therapy on the microvascular complications of type 1 diabetes mellitus. JAMA 287: 2563-2569, 2002.

HAMADA Y, NAKAMURA J, FUJISAWA H, YAGO H, NAKASHIMA E, KOH N, HOTTA N: Effects of glycemic control on plasma 3-deoxyglucosone levels in NIDDM patients. Diabetes Care 20: 1466-1469, 1997. 
HAN Y, RANDELL E, VASDEV S, GILL V, GADAG V, NEWHOOK LA: Plasma methylglyoxal and glyoxal are elevated and related to early membrane alteration in young, complication-free patients with type 1 diabetes. Mol Cell Biochem 305: 123-131, 2007.

HUEBSCHMANN G, REGENSTEINER JG, VLASSARA H, REUSCH JE: Diabetes and advanced glycoxidation end products. Diabetes Care 29: 1420-1432, 2006.

IHNAT MA, THORPE JE, CERIELLO A: Hypothesis: the 'metabolic memory', the new challenge of diabetes. Diabet Med 24: 582-586, 2007.

JONO T, NAGAI R, LIN X, AHMED N, THORNALLEY PJ, TAKEYA M, HORIUCHI S: N-epsilon(carboxymethyl)lysine and 3-DG-imidazolone are major AGE structures in protein modification by 3-deoxyglucosone. J Biochem 136: 351-358, 2004.

KALAPOS MP: On the mammalian acetone metabolism: from chemistry to clinical implications. Biochim Biophys Acta 1621: 122-139, 2003.

KIM W, HUDSON BI, MOSER B, GUO J, RONG LL, LU Y, QU W , LALLA E, LERNER S, CHEN Y, SHI DU YAN S, D'AGATI V, NAKA YU, RAMASAMY R, HEROLD K, YAN SF, SCHMIDT AM: Receptor for advanced glycation end products and its ligands: a journey from the complications of diabetes to its pathogenesis. Ann N Y Acad Sci 1043: 553-561, 2005.

KOSCHINSKY T, HE CJ, MITSUHASHI T, BUCALA R, LIU C, BUENTING C, HEITMANN K, VLASSARA H: Orally absorbed reactive glycation products (glycotoxins) - an environmental risk factor in diabetic nephropathy. Proc Natl Acad Sci USA 94: 6474-6479, 1997.

LAL S, SZWERGOLD BS, TAYLOR AH, RANDALL WC, KAPPLER F, WELLS-KNECHT KJ: Metabolism of fructose-3-phoshate in the diabetic rat lens. Arch Biochem Biophys 318: 191-199, 1995.

LAL S, RANDALL WC, TAYLOR AH, KAPPLER F, WALKER M, BROWN TR, SZWERGOLD BS: Fructose-3phosphate production and polyol pathway metabolism in diabetic rat hearts. Metabolism 46: 1333-1338, 1997.

LAPOLLA A, FLAMINI R, VEDOVA AD, SENESI A, REITANO R, FEDELE D: Glyoxal and methylglyoxal levels in diabetic patients: quantitative determination by a new GC/MS method. Clin Chem Lab Med 41: 1166-1173, 2003.

LO TWC, WESTWOOD ME, MCLELLAN AC, SELWOOD T, THORNALLEY PJ: Binding and modification of proteins by methylglyoxal under physiological conditions - a kinetic and mechanistic study with N-alphaacetylarginine, $\mathrm{N}$-alpha-acetylcysteine, and $\mathrm{N}$-alpha-acetyllysine, and bovine serum albumin. J Biol Chem 269: 32299-32305, 1994.

LUKIC IK, HUMPERT PM, NAWROTH PP, BIERHAUS A: The RAGE pathway: activation and perpetuation in the pathogenesis of diabetic neuropathy. Ann NY Acad Sci. 1126: 76-80, 2008.

LYLES GA, CHALMERS J: The metabolism of aminoacetone to methylglyoxal by semicarbazide-sensitive amine oxidase in human umbilical artery. Biochem Pharmacol 43: 1409-1414, 1992.

MAILLARD LC: Action des acides aminés sur les sucres: formation des mélanoïdines par voie méthodique. Réaction de Maillard. C R Acad Sci 154: 66-68, 1912.

MAKITA Z, BUCALA R, RAYFIELD EJ, FRIEDMAN EA, KAUFMAN AM, KORBET SM : Reactive glycosylation endproducts in diabetic uraemia and treatment of renal failure. Lancet 343: 1519-1522, 1994.

MCLELLAN AC, THORNALLEY PJ, BENN J, SONKSEN PH: Glyoxalase system in clinical diabetes mellitus and correlation with diabetic complications. Clin Sci 87: 21-29, 1994.

MISUR I, ZARKOVIC K, BARADA A, BATELJA L, MILICEVIC Z, TURK Z: Advanced glycation endproducts in peripheral nerve in type 2 diabetes with neuropathy. Acta Diabetol 41: 158-166, 2004.

MONNIER VM, SELL DR, GENUTH S: Glycation products as markers and predictors of the progression of diabetic complications. Ann NY Acad Sci 1043: 567-581, 2005.

NAGARAJ RH, SADY C: The presence of a glucose-derived Maillard reaction product in the human lens. FEBS Lett 382: 234-238, 1996.

NAKAJIMA K, OHTA K, MOSTEFAOUI TA, CHAI W, UTSUKIHARA T, HORIUCHI CA, MURAKAMI M: Glyoxal sample preparation for high-performance liquid chromatographic detection of 2,4-dinitrophenylhydrazone derivative: suppression of polymerization and mono-derivative formation by using methanol medium. J Chromatogr A 1161: 338-341, 2007. 
NEMET I, TURK Z, DUVNJAK L, CAR N, VARGA-DEFTARDAROVIC L: Humoral methylglyoxal level reflects glycemic fluctuation. Clin Biochem 38: 379-383, 2005.

NEMET I, VARGA-DEFTARDAROVIC L, TURK Z: Methylglyoxal in food and living organisms. Mol Nutr Food Res 50: 1105-1117, 2006.

NIWA T: 3-Deoxyglucosone: metabolism, analysis, biological activity, and clinical implication. J Chromatogr B 731 : 23-36, 1999.

NIWA T, TAKEDA N, MIYAZAKI T, YOSHIZUMI H, TATEMATSU A, MAEDA K. Elevated serum levels of 3-deoxyglucosene, a potent protein-cross-linking intermediate of the Maillard reaction, in uremic patients. Nephron 69: 438-443, 1995.

NIWA T, KATSUZAKI T, MIYAZAKI S, MIYAZAKI T, ISHIZAKI Y, HAYASE F: Immunohistochemical detection of imidazolone, a novel advanced glycation end product, in kidneys and aortas of diabetic patients. $J$ Clin Invest 99: 1272-1280, 1997.

NIWA T, TAKEDA N, YOSHIZUMI H, TATEMATSU A, OHARA M, TOMIYAMA S, ODANI H, SHINZATO T, MATSUMOTO Y, USAMI J, MAEDA K: Increase in three alpha, beta-dicarbonyl compound levels in human uremic plasma: specific in vivo determination of intermediates in advanced Maillard reaction. Biochem Biophys Res Commun 256: 89-93, 1999.

POKUPEC R, KALAUZ M, TURK N, TURK Z: Advanced glycation endproducts in human diabetic and non-diabetic cataractous lenses. Graefes Arch Clin Exp Ophthalmol 241: 378-384, 2003.

RABBANI N, SEBEKOVA K, SEBEKOVA K JR, HEIDLAND A, THORNALLEY PJ: Accumulation of free adduct glycation, oxidation, and nitration products follows acute loss of renal function. Kidney Int 72: 1113-1121, 2007.

RAMASAMY R, YAN SF, HEROLD K, CLYNES R, SCHMIDT AM: Receptor for advanced glycation end products: fundamental roles in the inflammatory response: winding the way to the pathogenesis of endothelial dysfunction and atherosclerosis. Ann NY Acad Sci 1126: 7-13, 2008.

RICHARD JP: Mechanism for the formation of methylglyoxal from triosephosphates. Biochem Soc Trans 21: 549-553, 1993.

SADY C, JIANG CL, CHELLAN P, MADHUN Z, DUVE Y, GLOMB MA, NAGARAJ RH: Maillard reactions by a-oxoaldehydes: detection of glyoxal-modified proteins. Biochim Biophys Acta 1481: 255-264, 2000.

SCHMIDT AM, YAN SD, WAUTIER JL, STERN D. Activation of receptor for advanced glycation end products - a mechanism for chronic vascular dysfunction in diabetic vasculopathy and atherosclerosis. Circ Res 84: 489497, 1999.

SHAMSI FA, NAGARAJ RH: Immunochemical detection of dicarbonyl-derived imidazolium protein crosslinks in human lenses. Curr Eye Res 19: 276-284, 1999.

SINGH R, BARDEN A, MORI T, BEILIN L: Advanced glycation end-products: a review. Diabetologia 44: 129-146, 2001.

THORNALLEY PJ: The glyoxalase system: new developments towards functional characterization of a metabolic pathway fundamental to biological life. Biochem J 269: 1-11, 1990.

THORNALLEY PJ: Glutathione-dependent detoxification of $\alpha$-oxoaldehydes by the glyoxalase system: involvement in disease mechanisms and antiproliferative activity of glyoxalase I inhibitors. Chem Biol Interact 111-112: 137 $151,1998$.

THORNALLEY PJ: Glyoxalase I - structure, function and a critical role in the enzymatic defence against glycation. Biochem Soc Trans 31: 1343-1348, 2003.

THORNALLEY PJ: Dicarbonyl intermediates in the Maillard reaction. Ann NY Acad Sci 1043: 111-117, 2005.

THORPE SR, BAYNES JW: Maillard reaction products in tissue proteins: new products and new perspectives. Amino Acids 25: 275-281, 2003.

THORPE SR, LYONS TJ, BAYNES JW: Glycation and glycoxidation in diabetic vascular disease. In: Oxidative Stress and Vascular Disease. KEANEY JF, (ed) Kluwer Academic Publishers, Norwell, MA, 2000, pp 259-285.

TRESSEL T, THOMPSON R, ZIESKE LR, MENENDEZ MITS, DAVIS L: Interaction between L-threonine dehydrogenase and aminoacetone synthetase and mechanism of aminoacetone production. J Biol Chem 261: 16428-16437, 1986. 
TSUKUSHI S, KATSUZAKI T, AOYAMA I, TAKAYAMA F, MIYAZAKI T, SHIMOKATA K, NIWA T: Increased erythrocyte 3-DG and AGEs in diabetic hemodialysis patients: role of the polyol pathway. Kidney Int $\mathbf{5 5}$ : 1970-1976, 1999.

TURK Z: Advanced glycation toxicity in diabetic complications. Diabetol Croat 26: 11-26, 1997.

TURK Z: Glycation and complications of diabetes. Diabetol Croat 30: 49-54, 2001.

TURK Z, LJUBIC S, TURK N, BENKO B: Detection of autoantibodies against advanced glycation endproducts and AGE-immune complexes in serum of patients with diabetes mellitus. Clin Chim Acta 303: 105-111, 2001.

TURK Z, ŠESTO M, SKODLAR J, FERENČAK G, POKUPEC R, TURK N, STAVLJENIC-RUKAVINA A: The products of advanced glycation in patients with type 2 diabetes and vascular disease. Ann Clin Biochem 40: 552-559, 2003.

TURK N, MORNAR A, MRZLJAK V, TURK Z: Urinary excretion of advanced glycation endproducts in patients with type 2 diabetes with various stages of proteinuria. Diabete Metab 30: 187-192, 2004.

TURK Z, NEMET I, VARGA-DEFTARDAROVIC L, CAR N: Elevated level of methylglyoxal during diabetic ketoacidosis and its recovery phase. Diabete Metab 32: 176-180, 2006.

URIBARRI J, PEPPA M, CAI W, GOLDBERG T, LU M, BALIGA S, VASSALOTTI JA, VLASSARA H: Dietary glycotoxins correlate with circulating advanced glycation end product levels in renal failure patients. $A m J$ Kidney Dis 42: 532-538, 2003.

WANG X, DESAI K, CLAUSEN JT, WU L: Increased methylglyoxal and advanced glycation end products in kidney from spontaneously hypertensive rats. Kidney Int 66: 2315-2321, 2004.

WANG X, DESAI K, CHANG T, WU L: Vascular methylglyoxal metabolism and the development of hypertension. J Hypertens 23: 1565-1573, 2005.

WANG Y, VOM HAGEN F, PFISTER F, BIERHAUS A, FENG Y, GANS R, HAMMES HP: Receptor for advanced glycation end product expression in experimental diabetic retinopathy. Ann NY Acad Sci 1126: 42-45, 2008.

WELLS-KNECHT KJ, LYONS TJ, MCCANCE DR, THORPE SR, FEATHER MS, BAYNES JW: 3-Deoxyfructose concentrations are increased in human plasma and urine in diabetes. Diabetes 43: 1152-1156, 1994.

YAMAMOTO H, WATANABE T, YAMAMOTO Y, YONEKURA H, MUNESUE S, HARASHIMA A, OOE K, HOSSAIN S, SAITO H, MURAKAMI N: RAGE in diabetic nephropathy. Curr Mol Med 7: 752-757, 2007. 